\title{
EXPERIMENTS IN THE TREATMENT OF LEPROSY WITH ETOXID (PRELIMINARY INFORMATION)
}

by V. K. Loginov, A. M. Letichevskaya, Interns R. A. Aksanova, G. A. KHRIKOV

of the Institute for the Study of Leprosy.

(Director Dr. V. F. SUBIN)

Translation by the kindness of Dr. J. I. MIRILOW.

(From the article published in Ucheniye Zapiski 3 (8)

Astrakhan 1962)

Recently information has appeared in literature (scientific literature) about the effectiveness in treatment of leprosy with a drug manufactured by CIBA-1906 or DPT. (INNES et al. 1957, DAVEY 1958, Gate 1958, Doull 1960, Davey 1960, Nazarov 1960). This was synthesized by American research workers HUEBNER el al. and made possible to be put on the market by the CIBA research workers. This drug proved to be effective in the treatment of tuberculosis in vivo as well as in vitro.

Compound 1906 was put on the market by a Swiss firm of CIBA and is composed of p-butoxy p-dimethylaminothiocarbanilide.

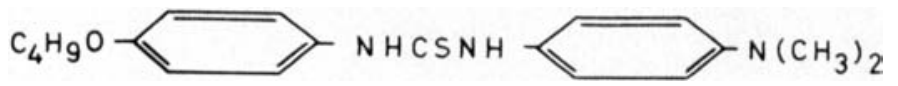

In the past year a number of medical preparations have emerged the present one being a derivative of diphenyl-thiourea which was recommended for the treatment of T.B. and leprosy.

In 1953 in the laboratories of Professor M. N. SHUKIN (The Institute for Scientific Research in Chemistry and Pharmacology of the U.S.S.R.) a compound was synthesized belonging to the group of thiocarbanilides, namely Etoxid which is in itself diethoxythiocarbanilide.

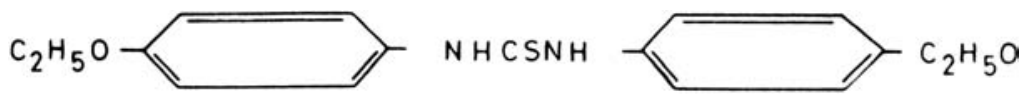

This is a white or slightly yellowish crystalline powder, bitter in taste, and it melts at a temperature of between $168-271^{\circ} \mathrm{C}$. It is insoluble in water, ether and chloroform but is soluble in acetone and alcohol. This preparation possesses a high bacteriological activity and has been selected with respect to bacteriocidal action on the mycobacterium of tuberculosis.

Growth of other pathogenic bacteria has been suppressed. A detailed publication about this synthesis was completed in 1960 by N. B. Galstukhova and M. N. Shukina. 
In our national literature we have a large amount of information about the effect in treatment of tuberculosis with Etoxid.

A. Kaminskaya and E. Z. Mirzoyan (1959) administered this drug to 48 patients with rather old and diffused pulmonary process. This was actually the introduction of the drug in the treatment of tuberculosis when certain other chemotherapeutic drugs had failed. Favourable progress was noted in 15 patients after X-rays were taken at the time of treatment and during a period of between $1 \frac{1}{2}-2$ months.

The drug acted effectively. In some of those patients it appeared to have decreased the catarrh and there was marked normalization in haemoglobin but less marked normalization of the leucocytosis. An increase in the number of lymphocytes was also noted.

N. A. Smelev (1960) noticed that application of Etoxid in the treatment of tuberculosis during the course of illness was well tolerated. Etoxid is the only one that does not combine with any other anti-tuberculosis drug and can bring about a process of resorption of the peripheral infiltrations (in leprosy).

G. N. Pershin and T. N. Zikova (1961) noticed the effectiveness of Etoxid as an anti-tuberculosis drug which exercised an antibacterial effect on Mycohacterium tuberculosis in vitro as well as in chemotherapeutic effects in the course of the experiments, for example in tuberculosis with white mice and guinea pigs. Etoxid possessed a therapeutic effect in patients suffering from different types of tuberculosis. At the same time the best results were achieved with Etoxid during the treatment of fresh cases of tuberculosis. Authors have recommended Etoxid as a drug for the treatment of tuberculosis where there was a positive presence of tubercle bacilli and stability towards streptomycin and pthivazid, etc.

M. N. SHukina (1961) has proved, by gathering all evidence she obtained during the clinical trials, that the drug possesses good therapeutic properties for the treatment of tuberculosis. Her information enabled us to pass that information on for the use of Etoxid on a wider basis. We also have clinical evidence which we obtained by testing that drug in connection with the treatment of leprosy. We have had under our care 24 male lepromatous patients, 11 male tuberculoid leprosy patients and another 11 male patients with the undifferentiated type of leprosy. There were 8 men and 16 women patients. In the age group up to 20 there was one male patient; in the age group 20 to 30,4 male patients; in the age group 31 to 40 , 1 male patient; in the age group 41 to 50,7 male patients; in the age group 50 to 60,5 male patients and over the age of 60,6 male patients.

During their illness they were classified in the following order. As far as the first year of treatment was concerned there were 4 male patients, between the first and the second year, 16 male patients and between 3 to 5 years 3 male patients and over 5 years one male 
patient. Before the introduction of Etoxid the lesions on the surface of the skin of the above patients treated previously with antileprosy drugs did not heal but on introducing Etoxid the results were good. So we introduced Etoxid in the following order. In the first week at 0.1 g. t.d.s. In the second week the dose was increased to $0.2 \mathrm{~g}$. t.d.s. and in the third and subsequent weeks $0.3 \mathrm{~g}$. also t.d.s.

At the beginning of the twenty-first week all those patients who were isolated had shown good tolerance in respect of the drug and the daily dose was increased up to $1.5 \mathrm{~g}$. That treatment was carried on for 40 weeks after which period followed a month of rest.

This course of treatment was administered to 15 male patients and the other patients were treated with Etoxid from between 4-8 months. In the group of patients who were affected with the lepromatous type of leprosy ( 11 male patients) there were characteristic infiltrative changes of varying degree. These infiltrative changes were manifested on the faces of these patients, on their extremities and in general on their bodies. In three of these patients nodules were dispersed on their bodies and all over their extremities. In the case of five men patients there was definite evidence of thickening of the ulnar nerves but we also had a case of one patient with a muscular atrophy and contraction in flexion of the thumbs on both hands. On histological examination of skin specimens taken from the affected parts there was a definite lepromatous structure of the infiltrations with an abundance of homogeneous leprosy bacilli. Tests in all these cases were negative.

There has been observed during treatment with Etoxid, which lasted between 14-21 weeks, a regression of the specific manifestations. Infiltrations were gradually reabsorbed and the colour became paler. On the other hand, some of these infiltrations disappeared and in place of them we observed spots. Later on the regressive changes became more and more noticeable; regression of infiltrations and nodules was complete, and the spots disappeared. Improvement was general, the patients felt much better, and they also gained between $2-9 \mathrm{~kg}$. When biopsy was repeated on the diseased portions of skin in 8 patients, it was noted that the second biopsy revealed infiltrations of the lepromatous type of leprosy, the infiltrations became smaller, fibrous changes appeared in the dermis, mycobacteria were noticeably reduced in number, and the disease manifested itself in the form of spots.

\section{CASE HISTORIES: General Notes}

(a) In one particular case a woman patient (case history No. 2890) was admitted with an infiltration of lepromatous type which was replaced later on after weeks of treatment by an infiltration of a rather 'roundish' type but without any evidence of the presence of Mycobacterium leprae. At that stage of treatment the connective tissue in the skin formed and went on to healing. The bacterial index became normal in 3 cases which previously had a reduced bacterial index.

In the case of 3 patients (sixth, twentieth and thirty-second week of treatment) there was a manifestation of a nodular type of erythema in all three cases but 
without an increase in temperature and without any deterioration in the general state of health, despite the erythema, treatment went on. The erythema complication gradually disappeared.

(b) In the case of patient $\mathrm{E}$ (case history No. 2932) during the course of treatment the presence was noted of elementary nodular erythema which appeared and disappeared periodically.

(c) In the case of patient P (case history No. 2963) we saw in the course of the second month of treatment that the lepromatous process did not react to the treatment as might have been expected. The lesions and the hyperpigmented spots acquired erythematous colouring and also showed up in new elements. The treatment was not discontinued. Soon after that the giving of the drug lesions in the form of erythema disappeared and the lepromatous process was healed in the normal course of regression treatment. Here are short notes (case histories) which may help.

Case No. 1. Female patient age 60 (case history No. 2939).

The patient was admitted to the Institute for the Study of Leprosy on the 21 st February 1960, and diagnosed as having the lepromatous type of leprosy. On her arrival at the Institute there were diffused infiltrations on her face, especially on her ears and ear lobes. In the region of her forehead and eyebrows the infiltrations were much deeper, and the eyebrows were rather sparse. On the upper and lower extremities marked infiltrations were observed which in places merged so that they formed infiltrations of the entire face. On the chest infiltrations were seen to be diffused, and some had clearly defined borders. A similar rash was observed on the buttocks and in the region of the hips. Along the tibia there were also diffused infiltrations in the form of flowers. Ulnar nerves were thickened on both arms and proved painful to palpation. ESR was $44 \mathrm{~mm}$. per hour. Lepromin tests were doubtful. Skin biopsy of the portions affected by leprosy showed numerous infiltrations of the lepromatous type with a great quantity of homogeneous leprosy bacilli. After eight weeks of treatment with Etoxid some of these infiltrations subsided and became paler, and after 20 weeks of treatment the appearance of reactionary elements showed in the form of erythemas of a nodular type on the upper as well as on the lower extremities but the treatment was not interrupted. Body temperature remained normal. The general condition did not worsen. After thirty weeks of treatment the nodular type of erythema disappeared. The infiltrative inflammatory process remained until the end of the first course of treatment. Later on the above mentioned manifestations on the surface of the skin regressed noticeably. Deeply marked infiltrations of the extremities and of the body remained there but became more superficial. The puffiness of the face disappeared and the patient gained $2 \mathrm{~kg}$. in weight. Nasal smear on October 1960 pointed clearly to a case of the lepromatous type of leprosy, but by repeating the examination of the nasal smear we noted that the causative organisms had disappeared. ESR was reduced to $22 \mathrm{~mm}$. per hour. By repeated histological examination of diseased portions of the skin we did not observe any characteristic regression of the lepromatous infiltrations, no more than it revealed any presence of the leprosy bacilli.

Case No. 2. Female patient age 68 (case history No. 2932).

The patient was admitted to the Institute for the Study of Leprosy on the 28th September 1960 with a lepromatous type of leprosy. At the time of her admission this patient's upper and lower extremities were diffusely infiltrated. There were prominent superficial infiltrations on the chest, back and the buttocks. The ulnar nerves were slightly thickened but painless on palpation. There was reduction of sensitivity on the lower extremities, especially in the lower third.

Bacterial Index was 2.3 and the lepromin test was negative. Biopsy of the skin revealed the presence of disease in the form of infiltrations of a lepromatous structure with homogeneous bacillary foci.

After twelve weeks of treatment there was a certain reaction of elements which showed erythema in the limbs. Fifteen weeks after commencement of treatment we observed thickening and pallor of the facial tissue due to infiltrations. The same thing was observed on the extremities. After completion of the full course of treatment there was a disappearance of infiltrations on the face as well as on the body and there was considerable regression. On the upper and lower extremities in the place of former infiltrations there were some marks left of hardly noticeable hyperpigmentation. The nodular erythema broke out and recurred sporadically for a certain period of time, almost throughout the whole course of treatment. Lepromin tests were negative. The bacterial index 
was normal. As far as the blood is concerned, we observed a reduction in haemoglobin down to $9.4 \mathrm{~g} . \%$. The patient was treated with Vitamin $\mathrm{B} 12$ and the haemoglobin went up to $12.6 \mathrm{~g} . \%$. After histological examination was carried out on a portion of the diseased skin it was found that the lepromatous infiltrations regressed as well as the destructive changes of Mycobacterium leprae.

Case No. 3. Male patient age 52 (case history No. 2914).

This patient was admitted to the Institute for the Study of Leprosy on the 22nd July 1960 with diagnosis of a lepromatous type of leprosy. At the time of his admission there were infiltrations on his face, principally localized on the forehead and around the eyebrows. There were diffused and deep "hilly" uneven infiltrations of the nose and the malar infiltrations were rather superficial and of a rosy red colour with a flowery pattern. On the superficial parts of the chest, back, buttocks and upper and lower extremit ies there were noticeable infiltrations with deep infiltrative marks and on the feet hyperkeratosis. On histological examination of affected portions of the patient's skin we found the presence of homogeneous leprosy bacilli and infiltrations of a lepromatous type.

The results of treatment with Etoxid were remarkable after only 15 weeks of treatment. After the course of treatment was completed the pronounced and deep infiltrative marks on the patient's face faded out and in their place was left only superficial infiltrations. On the upper and lower extremities the infiltrations disappeared as well as those on the rest of the body. No lepromatous reaction was noticed. The lepromin tests which were at first negative became slightly positive. This patient gained a total of $4 \mathrm{~kg}$. during his stay at the Institute.

Histological examination of the diseased portions of the skin revealed characteristic regressive changes of the lepromatous infiltration with the presence of leprosy bacilli.

In the group of patients affected with the tuberculoid type of leprosy ( 11 male patients) in 10 cases specific manifestations appeared on the surface of the dermis in a rather surprising form of papular 'limited' infiltrations. On histologicalexamination of diseased portions of the skin, in all these cases, there was definite evidence of disease and a loss of sensitivity in affected parts of the body. It was noted in six male patients, that thickening of ulnar nerves was prominent and there was loss of feeling in the area. Atrophy of the muscles and contraction on moving the thumbs was noticed in four men patients. Lepromin tests with different intensity were positive in all these cases. On histological examination of diseased portions of the skin there was definite proof that those patients suffered from typical infiltrations of the tuberculoid type of leprosy. Although in one case the clinical characteristics were pointing to the tuberculoid type of leprosy, it was found on histological examination of the diseased portion of skin that infiltration of the lepromatous type was present.

During treatment of the patients in the above-mentioned group we observed a relatively quick clinical effect in the majority of cases. In those cases which were isolated we found that regression took place after two to three weeks. The reduction of the extent of infiltrations was well manifested by pallor and limited infiltrations. Macules disappeared and became clearer and papules if present disappeared.

In three patients, in places where the tuberculoid type of leprosy was evident, the recovery took place also as in sensitivity of the affected parts. In no case did peripheral nerve damage increase. The treatment was tolerated extremely well and all patients gained about 
$1.6 \mathrm{~kg}$. On repeated histological examination of six of these patients it was found that infiltrative lesions of a tuberculoid type were replaced by infiltrations of the ordinary inflammatory type without any presence whatsoever of leprosy bacilli. Formation of fibrous tissue and connective skin tissue was also noted. In three patients lepromin tests which were originally slightly positive became fully positive.

In that particular group there were five patients where the regression of the lepromatous type of process was very distinctive and they were discharged from the Institute in order to follow up their treatment as outpatients.

Now we propose to illustrate with some notes from case histories some observations regarding the above mentioned patients.

1. Patient K., 49 years of age (case history No. 2967) was admitted to the Institute for Study of Leprosy on 26.1.61 with tuberculoid type of leprosy. On his admission it was found that marks of different size were present with clearly cut borders. On his chest, back, upper and lower extremities we have noted some type of round whitish skin marks. We have also seen in all these above mentioned skin manifestations already described, a limited reduction in patient's sensitivity. Ulnar nerves were thickened. In the upper and lower extremities there was a disturbance of sensitivity of the polyneuritic type. There was also an atrophy of the palmar muscles and muscular atony as well as a contraction of the third, fourth, and the fifth digits of the right hand when moving the digits. Lepromin tests were positive. Histological examination showed infiltrations of tuberculoid type without presence of leprosy bacilli as a result of one course only of treatment with Etoxid. The skin manifestations regressed and left afterwards hardly noticeable hyperpigmentation and the signs of atrophy of the skin. Contraction of the third, fourth and fifth digits of the right hand was to some extent decreased. Lepromin tests remained positive.

2. Woman Patient S., 65 years old (case history No. 2966) was admitted to the Institute for Study of Leprosy on 18.1.61 with widespread tuberculoid type of leprosy in an active stage. On the cheeks, ears, and the double chin, it was noticed that limited infiltrations were present in the shape of flowers with indistinct borders. There were on the body numerous papular lesions and on the extremities clear cut erythematous lesions. Superficial sensitivity of the rash was reduced. Peripheral nerve trunks were not thickened. Skin on the shins and the feet was dry and atrophic, and bacteriologically negative. Histologically infiltration was of tuberculoid type but without leprosy bacilli. Lepromin tests were slightly positive. Here are the results of one course of Etoxid treatment: namely regression of infiltrations of the affected parts and of the spotty rash, and in its place pale marks remained in a form of a flower.

On the histological examination of the skin, after a course of treatment with Etoxid, it was noticed that there was some infiltrations of ordinary inflammatory structure but without any evidence of the presence of leprosy bacilli. Lepromin tests remained positive. The patient was discharged in order to continue as an outpatient. Clinical manifestations of disease with undifferentiated leprosy (two patients only) were characterized by a multitude of hyperchromic and erythematous patches. In one case of a patient with such patches, a reduction or loss of sensation was noted. Peripheral nerve disease was not seen in a single case.

On histological examination of the portions of skin taken from diseased patients from different parts of the body, there was a definite presence of round foci of infiltration and leprosy bacilli were present in one case. In both the above mentioned cases, lepromin tests were slightly positive. After the treatment with Etoxid, a remarkable regression was noticed in both patients. In a case of one patient (case history No. 2996) lesions were hardly 
noticeable. Some scars had disappeared completely. Results of regression in that particular case was astonishing right from the start of the first week of the treatment.

Here I shall give you some details from a case history of another patient:

A woman patient 28 years old (case history No. 2958). She was admitted to the Institute for Study of Leprosy on 22.11.60 with diagnosis of undifferentiated type of leprosy. There was an evidence of a multitude of different marks of hyperchromic type on the surface of the skin on the patient's back, the buttocks and the extremities. Sensitivity on the surface of the skin was maintained. There were no evidence of damage done to the peripheral nervous trunks. Lepromin test results were slightly positive. On histological examination of the portions of skin there were simply small foci of infiltration of banal inflammatory structure but $M$. leprcie was present. After the usual treatment with Etoxid the hyperchromic scars completely disappeared.

Lepromin tests were strongly positive. On repeated histological examination small simple inflammatory type infiltrations were observed in the skin without the presence of leprosy bacilli.

\section{Summary}

In the Institute for the Study of Leprosy at Astrakhan the authors used in clinical trial a derivative of diphenylthiourea named Etoxid which is diethoxythiocarbanilide synthesized by $M$. N. SHUKIN. This compound was found to have a high bacteriocidal activity in tuberculosis and there are many reports in the Russian literature about its use in tuberculosis, e.g. A. KAMINSKAYA and E. Z. Mirzoyan, N. A. Smelev, G. N. Pershin and T. N. Zikova, M. N. Shukina, etc. In leprosy patients the authors report the use of Etoxid in a few cases in some detail. In lepromatous, tuberculoid and undifferentiated leprosy their results give a strong suggestion of significant clinical, bacteriological, and immunological improvement in a relatively short period of time, such as 15 weeks. The leprosy patients under treatment with Etoxid were 24 lepromatous, 11 tuberculoid, and 11 undifferentiated. The drug was given in a dosage of 0.1 g. t.d.s. moving weekly until 0.3 g. t.d.s. was reached. At the twenty-first week the dose was increased to $1.5 \mathrm{~g}$. and the treatment was carried on for 40 weeks followed by one month of rest.

\section{References}

Galstukhova, N. B., Shukina, M. N. : Med. Prom. U.S.S.R., 1960, No. 8, p. 15.

Kaminskaya, A. and Mirzoyan, E. Z. : Proba Tuberkuleza, 1959, No. 8, p. 47.

Nazarov, K. I., Letichevskaya, A. M., Khrikov, G. A., Bragina, V. C., Aksakova, R. A., Struchkova, V. H., and Linchevskaya, A. P.: Tezesi Doka shestoinayk sessin In-ta po izucheniu lepri, Astrakhan, 1960, p. 26.

Hermin, G. H. and Zikova, T. N.: Med. Prom. U.S.S.R., 1961, No. 64, p. 28.

Smelev, N. A.: Proba Tuberkuleza, 1960, No. 8, p. 27.

Shukina, M. N.: Med. Prom. U.S.S.R., 196i, No. 4, p. 13.

Davey, T. F.: Trans. roy. Soc. trop. Med. Hyg., 1960, 54, No. 3, p. 190.

Davey, T. F., Garret, A. S., Nicholson, B., Corcos, M., Fern. E., Matheson, R. and MacDonald, A.: Leprosy Rev., 1958, 29, No. 1, p. 25.

Doull, J. A.: J. Amer. Med. Ass., 1960, 173, p. 262.

Gate, J., Roussel, J. and Coudert, J.: Bull. Soc.frans. Derm. Syph., 1958, 65, p. 164.

Huebner, C. F., Marsh, J. L., Mizzoni, R. H., Mull, R. P., Schroeder, D. C., Froxell, N. A. and Scholz, S. R.: J. Amer. chem. Soc., 1953, 75, No. 9 , p. 2274.

InNes, J. R., Smith, M. and Harden-Smith, M.: E. Afr. med. J., 1957, 34, No. 7 , p. 394. 